\title{
Effect of ethanol on the anthocyanin extraction from the purple rice of Vietnam
}

\author{
Ninh Le thu Thao ${ }^{1}$, Dao Thi Kim Thoa ${ }^{1}$, Le Phuoc Thang ${ }^{1}$, Than Thi Ut Xi ${ }^{1}$, Dam Sao Mai ${ }^{1,}$, \\ Nguyen Thi Ngoc Tram ${ }^{2}$
}

${ }^{1}$ Institute of Biotechnology and Food technology, Industrial University of Ho Chi Minh City, Ho Chi Minh City,Vietnam

${ }^{2}$ Natural University of Ho Chi Minh City, Ho Chi Minh City, Vietnam

\author{
Email address: \\ damsaomai@gmail.com (D. S. Mai)
}

\section{To cite this article:}

Ninh Le thu Thao, Dao Thi Kim Thoa, Le Phuoc Thang, Than Thi Ut Xi, Dam Sao Mai, Nguyen Thi Ngoc Tram. Effect of Ethanol on the Anthocyanin Extraction from the Purple Rice of Vietnam. Journal of Food and Nutrition Sciences. Special Issue: Food Processing and Food Quality. Vol. 3, No. 1-2, 2015, pp. 45-48. doi: 10.11648/j.jfns.s.2015030102.18

\begin{abstract}
Anthocyanin is not only the common natural color, but also has potential applications such as the antioxidant component, and many other health benefits. This pigment has good application in the food industry. Purple rice (Oryza sativa) is a special cereal in Vietnam, and some other Asian countries. This rice contains high anthocyanin $(\sim 0.4 \%)$. The anthocyanin extraction was evaluated, and the best method of the extraction was determined. The experiment was conducted with the following variables: ethanol-to-water ratio as solvent $(\mathrm{E} / \mathrm{W}, 1: 9-6: 4)(\mathrm{v} / \mathrm{v})$, purple rice-to-water ratio $(\mathrm{P} / \mathrm{W}, 1: 6-1: 16)(\mathrm{w} / \mathrm{v})$, solvent $\mathrm{pH}(\mathrm{pH}, 2.0-3.0)$, solvent temperature $\left(\mathrm{ST}, 30-70{ }^{\circ} \mathrm{C}\right)$ and extraction time $(\mathrm{ET}, 60-180$ min). The result showed that the best adequate extraction conditions were $\mathrm{E} / \mathrm{W}, 2: 8 ; \mathrm{P} / \mathrm{W}, 1: 10 ; \mathrm{pH}, 2.2 ; 60^{\circ} \mathrm{C}$; and ET, 90min. At such condition, $116.7 \pm 5.8 \mathrm{mg} / 100 \mathrm{~g}$ anthocyanin was extracted.
\end{abstract}

Keywords: Oryza sativa, Anthocyanin, Food Color, Ethanol, Pigment Extraction

\section{Introduction}

Anthocyanins are considered secondary metabolites; it is a food additive E163. It is a natural pigment used quite safely in food; create more attractive colors for food products. At present, there are more than 300 anthocyanins which were identified the structure, including 6 main anthocyanins, such as: pelargonidin, cyanidin, delphinidin, peonidin, petunidin and malvidin.

The purple rice (Oryza sativa) consists of two main anthocyanins: cyanidin and peonidin. Those anthocyanins react like the antioxidant agents, which reduce the density of lipoprotein and reduce the nitric oxide formation (Zawistowski et al., 2003). Cyanidin helps to reduce the atherosclerotic plaque formation that was developed by lipid forming plaque (Wang et al., 2001). Chen et al., (2006) determined that peonidin helps to inhibit the cancer cell of human.

The anthocyanin molecule is not altered under the effect of intestinal bacteria in the stomach system of human. Thus, the anthocyanin molecules are also not changed in plasma and urine (Gui, and Rodriguez-Saona, 1999, Jon and David, 1998,
Passamonti et al., 2003). The recent studies showed that the anthocyanins are absorbed only at low levels, from $0.016 \%$ to $0.11 \%$, in human. Anthocyanins also protect the stomach lining against damage from oxidation, so delayed the early stages of stomach cancer and colon cancer (Halliwell, et al., 2000).

In this study, various anthocyanins extraction from the purple rice was investigated to achieve the highest extraction, for the selection of anthocyanin extraction methods to use in food industry.

The aim of this research was to focus on the optimum anthocyanin extraction by using ethanol from purple rice, which is grown in Vietnam.

\section{Materials and Methods}

Materials: The purple rice was collected from Soc Trang province, Vietnam. After collecting, the sample was storage in the dry place for use in the experiments.

The sample was ground into flour, and then the anthocyanin was extracted using ethanol solvent in suitable condition. The extracted solution was centrifuged (5000 
$\mathrm{rpm} / \mathrm{min}$ ) for $10 \mathrm{~min}$ to remove the sediment. To extract anthocyanin, vacuum rotary evaporator was used to get the high color content of the received liquid. (Dam Sao Mai, Le Van Tan, 2013)

Optimization of anthocyanin extraction: The ground purple rice were treated with different ratio of water and ethanol $(1: 9,2: 8,3: 7,4: 6,5: 5,6: 4(\mathrm{v} / \mathrm{v}))$, different ratio of raw material and selected solvent $(1: 6,1: 8,1: 10,1: 12,1: 14$, $1: 16(\mathrm{v} / \mathrm{v}))$ with different $\mathrm{pH}(2.0,2.2,2.4,2.6,2.8,3.0)$ at different temperature $\left(30,40,50,60,70^{\circ} \mathrm{C}\right)$, and different extraction time (1.0, 1.5, 2.0, 2.5, $3.0 \mathrm{hrs}$.).

Analysis:

The quantity of anthocyanins was determined by the $\mathrm{pH}$ differential method as described by Huynh et al (2004). This was simple method that measures the absorption of extracted liquid at two light wavelength $\lambda=520 \mathrm{~nm}$, and $\lambda=700 \mathrm{~nm}$ (the $\mathrm{A}_{\max }$ wavelength) at two different $\mathrm{pH},(1.0$ and 4.5). The results were then compared with standards anthocyanin measured under similar conditions.

The anthocyanins are calculated as cyanidin-3-glucoside equivalents, $\mathrm{mg} / \mathrm{L}$, using the following equation:

$$
\text { The measured anthocyanins }=\alpha=\frac{A \times M W \times D F \times 10^{3}}{\varepsilon \times l}(\mathrm{~g})
$$

where

$\mathrm{A}=\left(A_{520 \mathrm{~nm}}-A_{700 \mathrm{~nm}}\right) \mathrm{pH} 1.0-\left(A_{520 \mathrm{~nm}}-A_{700 \mathrm{~nm}}\right) \mathrm{pH} 4.5$;

MW (molecular weight) $=449.2 \mathrm{~g} / \mathrm{mol}$ for cyanidin-3glucoside (cyd-3-glu);
$\mathrm{DF}=$ dilution factor $(1: 10) ; 1=$ path length in $\mathrm{cm}$;

$\varepsilon\left(=26900\right.$ molar extinction coefficient, in $\mathrm{L} \cdot \mathrm{mol}^{-1} \cdot \mathrm{cm}^{-1}$, for cyd-3-glu;

$10^{3}=$ factor for conversion from $\mathrm{g}$ to $\mathrm{mg}$.

$$
\% \text { total antocyanins }=\frac{a}{m(100-w) \cdot 10^{-2}} \times 100 \%
$$

where $\mathrm{a}=$ the measured anthocyanins $(\mathrm{g}) ; \mathrm{m}=$ initial materials, $\mathrm{w}=$ the moisture contents of raw material $(\%)$

Statistical analysis: All the analyses were done in triplicate and measurement was done using Modde 5 software to perform optimization. Analyses of Variance (ANOVA) were conducted by using SPSS Version 13.0 for Windows (SPSS). Turkey tests were performed to test the significant differences between the mean values for treatments $(\mathrm{p}<0.05)$

\section{Results and Discussion}

\subsection{Effect of the Ratio between Water and Ethanol of the Extraction Solvent on the Amount of Anthocyanins}

Anthocyanins consist of hydrocarbon, which is water resistant, but they also have the polyphenol compounds that are highly soluble in water and polarized solvent. That's why the suitable solvent for anthocyanins extraction should be chosen from the organic solvent and then mixes with water, which is safe for human health and cheap.

Table 1. The effect of water and ethanol ratio on the anthocyanin extraction

\begin{tabular}{llll}
\hline Sample & Ratio of water and ethanol & Amount of extracted anthocyanin $(g)$ & Concentration of extracted anthocyanin from raw material (\%) \\
\hline $\mathrm{M}_{1}$ & $1: 9$ & $0.00705361^{\mathrm{bc}}$ & $0.078460^{\mathrm{bc}}$ \\
$\mathrm{M}_{2}$ & $2: 8$ & $0.00750448^{\mathrm{d}}$ & $0.083475^{\mathrm{d}}$ \\
$\mathrm{M}_{3}$ & $3: 7$ & $0.00728906^{\mathrm{cd}}$ & $0.081079^{\mathrm{cd}}$ \\
$\mathrm{M}_{4}$ & $4: 6$ & $0.00702856^{\mathrm{b}}$ & $0.078182^{\mathrm{b}}$ \\
$\mathrm{M}_{5}$ & $5: 5$ & $0.00638231^{\mathrm{a}}$ & $0.070993^{\mathrm{a}}$ \\
$\mathrm{M}_{6}$ & $6: 4$ & $0.00617191^{\mathrm{a}}$ & $0.068653^{\mathrm{a}}$ \\
\hline
\end{tabular}

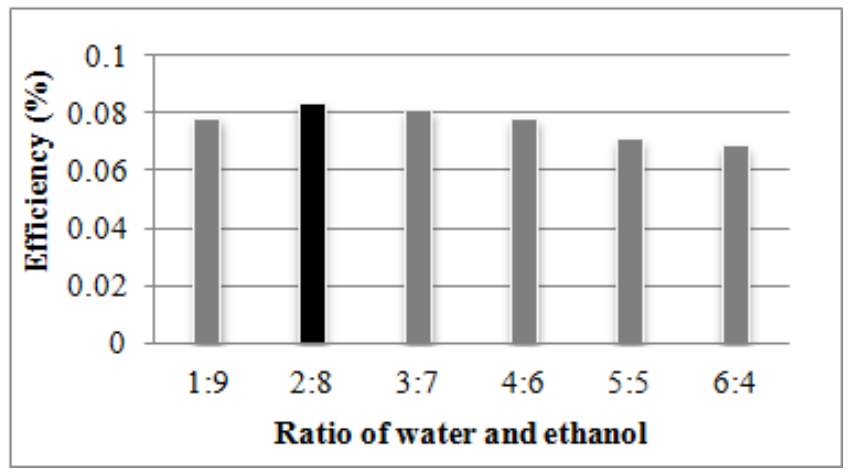

Fig. 1. The effect of water and ethanol ratio on the amount of anthocyanin extraction

This evaluation investigated the ratio of water and ethanol, which was used as extracting solvent. Data presented in Table 1 and Fig. 1 showed that, when unsuitable ratio of ethanol was used, the anthocyanins content in the extracted liquid was not high enough. When ratio of water: ethanol was: $1: 9,2: 8,3: 7$, and $4: 6$, the anthocyanins content in the extracted liquid was stable and nearly equivalent. Among this ratio of water and ethanol as 2: 8 ratios showed the best result. This result was used for the following study.

\subsection{Evaluation of the Amount of Solvent Requirements for the Anthocyanins Extraction}

This study used the best solvent ratio to extract anthocyanins from the purple rice. Data presented in Table 2 and Fig. 2 showed that, when the amount of solvent was too low, the anthocyanins were not extracted. The raw material and solvent ratio $1: 10$ and 1:16 gave the best results, and a non-significant difference was observed between the mean values for treatments. From the economic viewpoint, raw material and solvent ratio 1:10 was found more economical. 
Table 2. The effect of raw material and solvent ratio on the anthocyanin extraction

\begin{tabular}{llll}
\hline Sample & Ratio of raw material and solvent & Amount of received anthocyanin (g) & Concentration of received anthocyanin from raw material (\%) \\
\hline $\mathrm{M}_{1}$ & $1: 6$ & $0.006837^{\mathrm{a}}$ & $0.076058^{\mathrm{a}}$ \\
$\mathrm{M}_{2}$ & $1: 8$ & $0.007013^{\mathrm{a}}$ & $0.078014^{\mathrm{a}}$ \\
$\mathrm{M}_{3}$ & $1: 10$ & $0.007438^{\mathrm{b}}$ & $0.082733^{\mathrm{b}}$ \\
$\mathrm{M}_{4}$ & $1: 12$ & $0.007462^{\mathrm{b}}$ & $0.082999^{\mathrm{b}}$ \\
$\mathrm{M}_{5}$ & $1: 14$ & $0.007468^{\mathrm{b}}$ & $0.083067^{\mathrm{b}}$ \\
$\mathrm{M}_{6}$ & $1: 16$ & $0.007474^{\mathrm{b}}$ & $0.083142^{\mathrm{b}}$ \\
\hline
\end{tabular}

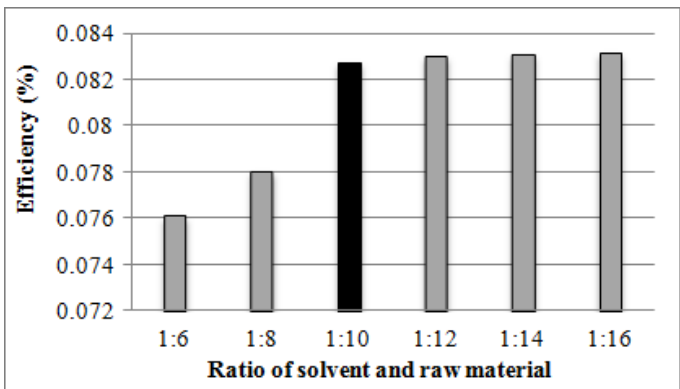

Fig. 2. The effect of ratio of raw material and solvent on capacity of the anthocyanin extraction

\subsection{Evaluation of the Solvent Optimal pH on Anthocyanins Extraction}

The $\mathrm{pH}$ of the solvent plays an important role during anthocyanin extraction from the purple rice with best solvent raw materials ratio. Data showed in Table 3 and Fig. 3 revealed that when the $\mathrm{pH}$ was high, the anthocyanin might be destroyed, so the extracted amounts were very low. The highest amount of anthocyanin $(0.035938 \%)$ was obtained at $\mathrm{pH}$ of 2.2. The results showed that a $\mathrm{pH}$ of $<2.2$ and $>2.4$ would be best to achieve high anthocyanin. This result is in agreement with other reported research results.

Table 3. The effect of the extraction $\mathrm{pH}$ on the anthocyanin extraction

\begin{tabular}{llll}
\hline Sample & Extraction pH & Amount of received anthocyanin (g) & Concentration of received anthocyanin from raw material (\%) \\
\hline $\mathrm{M}_{7}$ & 2.0 & $0.00790859^{\mathrm{a}}$ & $0.087971^{\mathrm{a}}$ \\
$\mathrm{M}_{8}$ & 2.2 & $0.00826261^{\mathrm{d}}$ & $0.0919089^{\mathrm{d}}$ \\
$\mathrm{M}_{9}$ & 2.4 & $0.0081023^{\mathrm{c}}$ & $0.0901257^{\mathrm{c}}$ \\
$\mathrm{M}_{10}$ & 2.6 & $0.00792863^{\mathrm{a}}$ & $0.0881939^{\mathrm{a}}$ \\
$\mathrm{M}_{11}$ & 2.8 & $0.00773492^{\mathrm{b}}$ & $0.0860392^{\mathrm{b}}$ \\
$\mathrm{M}_{12}$ & 3.0 & $0.00764141^{\mathrm{b}}$ & $0.084999^{\mathrm{b}}$ \\
\hline
\end{tabular}

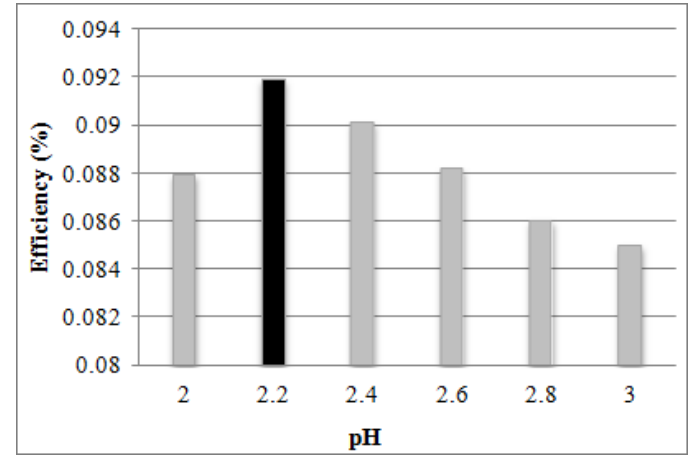

Fig. 3. The effect of the extraction $\mathrm{pH}$ on the capacity of the anthocyanin extraction

\subsection{Evaluation of the Solvent Optimal Temperature for Anthocyanins Extraction}

The extraction temperature might have influence on the ability to extract anthocyanins from samples. It was observed that increasing temperature was increased the ability of anthocyanins extraction by reducing the viscosity of the solution, while increasing the speed of diffusion of solutes from the material to the solvent. The highest concentration of anthocyanins was achieved at $60^{\circ} \mathrm{C}$. At $70^{\circ} \mathrm{C}$ temperature the quality of anthocyanins reduced rapidly, because the anthocyanins were susceptible denaturized by higher temperature. hence, the optimal temperature for the extraction was $60^{\circ} \mathrm{C}$. (Table 4, Fig. 4).

Table 4. The effect of the extraction temperature on the anthocyanin extraction

\begin{tabular}{llll}
\hline Sample & Extraction temperature $\left({ }^{\circ} \mathbf{C}\right)$ & Amount of received anthocyanin $(g)$ & Concentration of received anthocyanin from raw material $(\%)$ \\
\hline $\mathrm{M}_{7}$ & 30 & $0.00823589^{\mathrm{a}}$ & $0.0916117^{\mathrm{a}}$ \\
$\mathrm{M}_{8}$ & 40 & $0.00880699^{\mathrm{b}}$ & $0.0979643^{\mathrm{b}}$ \\
$\mathrm{M}_{9}$ & 50 & $0.00978555^{\mathrm{c}}$ & $0.108849^{\mathrm{c}}$ \\
$\mathrm{M}_{10}$ & 60 & $0.0111749^{\mathrm{d}}$ & $0.124304^{\mathrm{d}}$ \\
$\mathrm{M}_{11}$ & 70 & $0.00963526^{\mathrm{c}}$ & $0.107177^{\mathrm{c}}$ \\
\hline
\end{tabular}




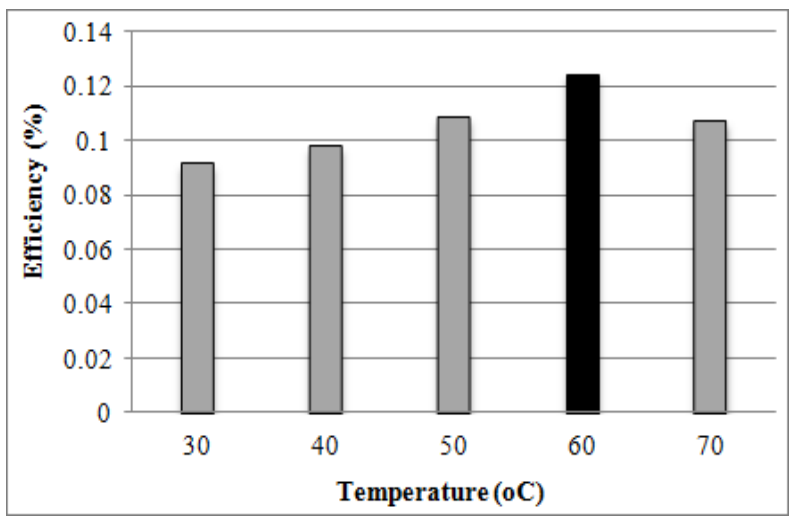

Fig. 4. The effect of the extraction temperature on the capacity of the anthocyanin extraction

\subsection{Evaluation of the Optimal Extraction Time on the Anthocyanin Extraction}

The extraction time affected to the ability of the anthocyanins extraction. If the extraction time (lower than $1.5 \mathrm{hrs}$ ) was too short, the anthocyanins did not come to the extracted liquid. on the other hand, if the extraction time was too long, anthocyanins got oxidized and the quality and quantity of anthocyanins reduced quickly. Table 5 showed that, when the sample was extracted in longer than $2.5 \mathrm{hrs}$, the amount of anthocyanins was reduced. The quantity of anthocyanins increased, and gave the best result from 1.5 to $2.5 \mathrm{hrs}$ of extraction; the extracted amount of anthocyanin showed non-significant differences between the mean values of treatment times. From the economic viewpoint, extraction time $1.5 \mathrm{hrs}$ was found sustainable (Table 5, Fig. 5).

Table 5. The effect of the extraction time on the anthocyanin extraction

\begin{tabular}{llll}
\hline Sample & Extraction time (hrs) & Amount of received anthocyanin $(g)$ & Concentration of received anthocyanin from raw material (\%) \\
\hline $\mathrm{M}_{27}$ & 1.0 & $0.0101162^{\mathrm{a}}$ & $0.112527^{\mathrm{a}}$ \\
$\mathrm{M}_{28}$ & 1.5 & $0.0116725^{\mathrm{b}}$ & $0.129839^{\mathrm{b}}$ \\
$\mathrm{M}_{29}$ & 2.0 & $0.0116759^{\mathrm{b}}$ & $0.129876^{\mathrm{b}}$ \\
$\mathrm{M}_{30}$ & 2.5 & $0.0116425^{\mathrm{b}}$ & $0.129505^{\mathrm{b}}$ \\
$\mathrm{M}_{31}$ & 3.0 & $0.0103333^{\mathrm{a}}$ & $0.114942^{\mathrm{a}}$ \\
\hline
\end{tabular}

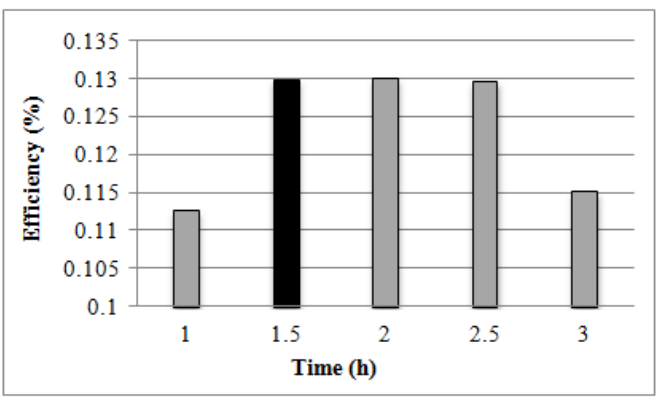

Fig. 5. The effect of the extraction time on the capacity of the anthocyanin extraction

\section{Conclusion}

This study results demonstrated that anthocyanin extraction is better when solvent (water: ethanol) ratio 2:8, raw material and solvent ratio $1: 10$, extraction time $1.5 \mathrm{hrs}$, $\mathrm{pH} 2.2$ and temperature $60^{\circ} \mathrm{C}$. This extraction condition was able to extract $0.1298 \%$ of anthocyanin from purple rice. The anthocyanin is one of the good components for human health, therefore, this extraction method could be applicable in food processing industries.

\section{References}

[1] Fuleki, T., Francis, F.J. 1968. Quantitative Methods for Anthocyanins. 2. Determination of total anthocyanin and degradation Index for Cranberry Juice. J. Food Science,
Vol.33.

[2] Gui, M. M., Rodriguez-Saona. 1999. Wrolslated PelargonidinBased Anthocyanins. J.Agric. and Food Chemistry, Vol. 47, No.11.

[3] Halliwell B, Zhao K, Whiteman M. 2000 The gastrointestinal tract: a major site of antioxidant action? Free Radic Res $33: 819-830$

[4] Huynh thi Kim Cuc, Pham Chau Quynh, Nguyen Thi Lan, Tran Khoi Uyen - 2004 Determination of anthocyanin content in fruits and vegetables by $\mathrm{pH}$-differential spectrophotometry - Scientist journal, University of Da Nang, N7, pp47-53

[5] Jon Wright and David Wickard. 1998. Biochemistry 321. The National Science Foundation.

[6] Passamonti, S., Vrhovsek, U., Vanzo, A., Mattivi, F., 2003. The stomach as a site for anthocyanins absorption from food. Federation of European Biochemical Societies Letters 544, 210-213

[7] Wang.T., et al., 2001. Red and Black rice decrease atherosclerotic paque formation and increase antioxidant status in rabbits. Am J, Nutr Sci., vol 131 (5); pp 1421-26

[8] Zawistowski .J., et al., 2003. Black rice (Oryza sativa L.. indica) pigment fraction suppresses both reactive oxygen species and nitric oxide in chemical and biological model systems. J Agri. Food Chem. Vol 52, pp 2213-17

[9] Dam Sao Mai, Le Van Tan. 2013. Study the Anthocyanin Extraction from the Rind of Mangosteen (Garcinia Mangostana) in Vietnam, $2^{\text {nd }}$ International Conference on Environment, Energy and Biotechnology. IPCBEE vol.51. 